\title{
Las nuevas dimensiones de la política externa brasileña
}

Toda política exterior resulta de un intento de compatibilizar necesidades internas con posibilidades externas. En estas interacciones existen datos inmutables, como el de la localización geográfica de un país en una determinada región del globo, y ciertos factores externos de mayor durabilidad, como el de la estructuración de poder en escala mundial, que explican las líneas de continuidad que, como regla, orientan una política externa. Por eso, cuando se la compara con la política interna ella tiene un ritmo más lento, de una coherencia derivada de ciertos intereses básicos condicionados por la relativa estabilidad de las modalidades posibles de inserción de un país en el sistema internacional.

A esta relativa estabilidad, que aclara la coherencia sintáctica de una diplomacia, una política externa competente siempre agrega una apertura, por así decir, semántica, un cambio de las circunstancias internas y externas y una evaluación pragmática de los recursos àe poder de que dispone un país para armonizar, de la mejor manera posible, el cuadro interno de las necesidades y el cuadro externo de las posibilidades.

La armonización de las necesidades internas con las posibilidades externas, o sea, la propuesta de inserción de un país en el mundo, se hace en tres significativos campos de actuación: el campo estratégico-militar, que traduce lo que un pafs significa o puede significar para otros como aliado, protector o enemigo en términos de riesgos de guerra y deseos de paz; el campo de las relaciones económicas, que explicita la importancia efectiva o potencial de un baís para otros como mercado; y el campo de valores, que revela la importancia de un país en cuanto modelo más o menos afín de una vida en sociedad. La actuación de un país en estos tres campos se hace, a su vez, en diferentes contextos diplomáticos, entre los cuales cabe destacar el de las grandes potencias, o sea, el de los paises que por el poder que detentan buscan establecer los parámetros estructuradores del orden mundial: el contexto regional, que resu!ta de las interrelaciones que ocurren entre países que comparten una misma área geográfica y el contexto contiguo, que es el que 
dice respecto a la interacción entre países que tienen fronteras en común.

Estas consideraciones analíticas son útiles en el examen de las nuevas dimensiones de la política exterior brasileña, pues permiten identificar cuáles son los factores de cambio que, combinados con los de la persistencia, han estado presidiendo los rumores diplomáticos del país.

El primer factor decisivo de cambio es de naturaleza interna. Se refiere a la transición pacífica hacia la democracia después de veinte años de régimen militar. La democracia, que en el Brasil está buscando instaurar una nueva Repúblj.ca, tiene como nota específica no sólo un reencuentro del Estado con la sociedad, sino también con las realidades y la escala de las necesidades de un país muy diferente de aquel que existía en 1964, cuando la intervención militar, en parte provocada por una crisis de gobernabilidad, interrumpió la experiencia democrática de la así llamada República Populista, iniciada en 1945 y señalada por el inicio de la extensión de las franquicias políticas, sociales y económicas de la población.

En efecto, desde 1964 hasta 1984 fue muy significativa la magnitud de los cambios ocurridos en el Brasil, comenzando por la demografía. En 1960, la población del Brasil era de 71 millones de habitantes y en 1985 era de 134,8 millones, de los cuales el $47 \%$ era menor de 20 años. En estos dos últimos decenios, Brasil se volvió la décima economía del mundo en volumen de producción, ingresó en la fase de los países mayoritariamente urbanos, pasó a tener una gran estructura industrial, diversificada y razonablemente bien equilibrada. Tanto en el campo como en la ciudad pasaron a prevalecer relaciones de trabajo asalariados. En el ámbito de la sociedad civil ganaron fuerza movimientos asociativos, desde el nuevo sindicalismo del Gran São Paulo hasta las comunidades eclesiales de base. Greció y se diversificó la pauta de exportaciones, que dejó de estar representada preponderantemente por productos primaarios.

A estos aspectos indicativos de la escala del cambio modernizador del país, cabe añadir la sombra del agravamiento de las desigualdades. Los más pobres - la mitad de la población brasileña-que en 1960 tenían sólo el 39\% de la renta nacional, hoy tienen menos del 30\%. E1 10\% más rico, que en 1960 tenían el 39\% de Ia renta nacional actualmente tienen el $51 \%$. Más de la mitad de las familiạs brasileñas se encuentran en una faja que varía de la estricta miseria (rendimientos de hasta un salario mínimo) a la estricta pobreza (rendimientos de hasta dos salarios mínimos), haciendo notar que el salario mínimo, cuando Sarney tomó posesión de su cargo de Presidente de la República, era de US\$25 por mes. Eso se refleja en Ios indicadores sociales, que sitúan al Brasil en esta materia poco 
por encima del quincuagésimo lugar en el "ranking" mundial, como se puede ver en el deterioro de la vivienda y en la degradación dc la vida urbana representada por la violencia y la criminalidad.

En sintesis, el Brasil se caracteriza por el enorme contraste entre sus indicadores económicos, que lo señalan como un país próximo al desarrollo y sus indicadores sociales, que lo sitúan como un país efectivamente subdesarrollado.

Para la Nueva República, que asumió un compromiso fundamental con la democracia y con el cambio, parece evidente que la necesidad interna número uno del Brasil, derivada de sus realidades, es la erradicación de la miseria y de los mecanismos que la reproducen. De hecho, sin un patrón de vida digno para todos los ciudadanos, no se institucionalizarán de manera duradera en el pás ni la democracia como forma de vida y de gobierno ni una economía de mercado estable. Como dice el Presidente Sarney en la Organización de Estados Americanos el 11 de septiembre de 1986: "en América Latina la democracia no es todavía una conquista definitiva. Es ardua batalla, lucha cotidiana para llevar la participación a todos los sectores de la vida y no sólo al nivel político".

"No podemos huir de responsabilidades ineludibles. La historia no nos colocó en posición de importancia en la vida de nuestros parses para asistir impasibles al correr del tiempo, para ser administradores de una eterna esperanza, de una confianza inerte, en espera de que estas tierras se transformen por sí solas en un nuevo mundo".

¿Cuáles son las consecuencias de este cambio interno para la polftica exterior brasileña? Creo que en primer lugar cabe destacar que el compromiso de la Nueva República con la democracia y la tolerancia inherente al pluralismo corresponde, en el plano externo, a un internacionalismo de vocación pacífica, guiado por los preceptos de la coexistencia y cooperación con todos los demás miembros de la sociedad internacional. Esta es una razón de principio para explicar el reciente restablecimiento de relaciones diplomáticas con Cuba, que completa la vocación ecuménica de la politica externa brasileña. De hecho, de la propuesta democrática interna abierta a la representación legal de todas las corrientes de opinión, se deriva también la convicción doctrinaria de que los intereses nacionales orientados a la ampliación del poder de control de la sociedad brasileña sobre su propio destino y a la reducción de las desigualdades, pueden ser promovidos adecuadamente. Esto, sin exclusiones, pero evidentemente con mayor o menor intensidad en función de los campos de actuación y de los contextos diplomáticos, en relación a todos los estados, por vía diplomática, a través de la persuasión, del compromiso y de la presión, medios típicos de la convivencia democrática. 
El internacionalismo pacífico de la Nueva República inaugura una convergencia plena entre la propuesta externa de democratización de las relaciones internacionales, que ha caracterizado la acción de Itamaraty en los últimos años del régimen militar, y del proceso interno. "No pediremos al mundo to que no hagamos dentro de nuestras fronteras", dice el Presidente Sarney en la apertura de los trabajos de la Asamblea General de la onv el 23 de septiembre de 1985, pues "estamos reconciliados. Nuestra fuerza pasó a ser coherencia".

Esta coherencia es importante para la actuación del país en el campo de los valores, pues la conducta externa de los estados no sólo está dominada por las relaciones de fuerza e intereses militares o económicos.

Las ideas, sentimientos, percepciones, también influyen en las decisiones de los protagonistas del sistema internacional. Por eso se puede decir que toda política externa combina aspectos cuantitativos y cualitativos. Entre los primeros, que están vinculados al campo de los valores, está la legitimidad internacional, o sea, el título para actuar y la "vis atractiva" que deriva de las democracias en el plano interno. Por esta razón el Presidente Sarney se sintió autorizado a afirmar, en su discurso ya citado en la oNU en septiembre de 1985: "Deseamos ahora vigorizar con redoblado interés nuestra presencia en el debate de las naciones".

Ese robustecimiento cualitativo de la presencia internacional del Brasil es una nueva dimensión de la política externa. En el campo de los valores, ella se traduce en la solidaridad con otros Estados que comparten los ideales y la práctica de la democracia, muy particularmente aquellos del contexto regional latinoamericano, como es el caso de Argentina y de Uruguay, y por la profundización del repudio al "apartheid" en Africa del Sur. De esta postura también se deriva una nueva e inédita directriz diplomática en materia de derechos humanos. Ésta está representada por la inequfvoca manifestación de la voluntad del Ejecutivo en adherir a los dos grandes pactos de la onu sobre derechos humanos, la Convención Americana sobre Derechos Humanos, la Convención de la onv y la Convención Interamericana para la Prevención y el Castigo de la Tortura. Así se supera el conflicto sobre derechos humanos que, durante el régimen militar, por obra del arbitrio y la no prestación de cuentas a la comunidad internacional, deslegitimaba la posición del país en cuanto abogado de la democratización del poder mundial.

Cabe también mostrar que el fortalecimiento cualitativo de la presencia internacional del Brasil amplía sus posibilidades de actuación. En efecto, una política externa requiere, además de una propuesta adecuada de inserción del país en el mundo, un estilo, o sea, modalidades de actuación que señalan recursos de competencia 
y habilidad que, cuando se emplean bien, refuerzan $y$, cuando se utilizan mal, comprometen la politica internacional de un pafs. Un estilo competente realza cualitativamente los recursos de poder de un país y minimiza sus flaquezas, al promover los intereses nacionales por medios diplomáticos, vale decir, por la persuasión, por el compromiso y por la presión.

El Brasil, gracias al profesionalismo de sus cuadros diplomáticos, siempre tuvo estilo, pero en este capítulo la Nueva República abrió la posibjilidad de una diplomacia presidencial en moldes que no estaban al alcance del régimen militar. De hecho, la democracia está permitiendo al país colocar, por la voz y por la presencia de su Presidente, en una nueva dimensión y con más fuerza de atracción, los intereses nacionales en las más altas instancias de la discusión bilateral y también en los foros multilaterales.

Ese tipo de diplomacia que asegura prioridad en la transmisión de una posición en la Nueva República, se inició con la visita del presidente electo Tancredo Neves en enero y febrero de 1985 al Papa, a los diversos países de América Latina -todos democráticos-, cuyo objetivo era obtener el reconocimiento cualitativo de una solidaridad proveniente de formas comunes de concebir la vida en sociedad. Esta postura en el momento actual está siendo conducida y profundizada por el Presidente Sarney y busca reforzar el peso del Brasil como interlocutor respetable en el nivel internacional, ya sea en el plano de la convergencia -como fue el caso de los encuentros con el Presidente Alfonsín, de Argentina, o con el Presidente Sanguinetti, de Uruguay- ya sea en el plano de la divergencia, como fue el caso del reciente encuentro con el Presidente Reagan, de los EE. Uu. Dicho lo que se acaba de expresar sobre valores, principios y estilo, se derivan consecuencias importantes para la política exterior del Brasil en los campos estratégico-militar y económico. En el campo estratégico-militar, caracterizado por los riesgos de guerra y las ansias de paz que permean la vida de los pueblos y de las naciones y configuran el parámetro último del orden internacional, la Nueva República ha venido sosteniendo el tradicional principio de la diplomacia brasileña de condena de las guerras de conquista y reafirmando la importancia de la solución pacífica de las controversias y de la no injerencia en los asuntos externos de otros estados. Esta postura es una consecuencia de la posición del Brasil en el sistema internacional.

En efecto, para países como el Brasil, la paz no es sólo la inexistencia de guerra nuclear y de operaciones militares convencionales de gran escala, (como para las grandes potencias actuales, EE. UU. y URSs), sino también la seguridad, representada por la inmunidad y la agresión, y por la preservación de la soberanía y de la integridad territorial de todos los e:tados, gxandes y pequeños. Por esta razón, 
el Brasil, frente a la persistencia de focos de conflictos militares en América Central, está profundizando su postura favorable a una solución negociada de cuño latinoamericano en el ámbito del proceso de Contadora. Al integrar el grupo de Apoyo a Contadora, la Nueva República reafirmó, con un vigor que no había caracterizado la diplomacia del régimen militar, su apoyo a las formas políticas conciliatorias que restablezcan en la región un diálogo con base en el pluralismo de opiniones, tanto en el plano interno como en la interacción entre los estados.

Esta postura más afirmativa se desdobló en la reciente iniciativa del gobierno de Sarney -sometida en 1986 a la Asamblea General de la ONU- de convertir el Atlántico Sur en una zona de paz, militarmente desnuclearizada. Esta iniciativa es un puente de naturaleza política entre África y América del Sur, y quiere colocar en la agenda del campo estratégico militar la aspiración brasileña de no ver al país enredado: en los imponderables simplificadores del conflicto Este-Oeste. De hecho, en las perspectivas de una potencia intermedia como el Brasil, situada geográficamente en el sur del continente americano con graves problemas internos de desigualdad, el conflicto Este-Oeste no capta toda la complejidad, extensión y urgencia de los problemas presentes en el orden del día del sistema internacional.

El desarme y otros mecanismos de control y reducción de los medios de guerra son importantes para el Brasil también, en uno de sus contextos diplomáticos más relevantes: el de sus vecinos, insertados a su vez en el contexto regional más amplio de América Latina. El Brasil convive - y necesita convivir- pacíficamente con sus diez vecinos, un dato importante y permanente de su política externa y que exige una actuación diplomática constante. Es de sumo interés para el Brasil el que, tanto Ios focos de guerrilla y de terror en Colombia y Perú como las controversias territoriales pendientes en América del Sur (por ejemplo, Perú y Ecuador, Perú y Ghile, Venezuela y Guyana), sean resueltos por la concordia de la negociación, tomando ejemplo en el reciente acuerdo argentino-chileno sobre el Beagle, obtenido a través de la mediación papal. Esa es la tradición y también la práctica reciente del Brasil, que superó a través del acuerdo, incluso durante la vigencia del régimen militar, la controversia de los años 70 con Argentina, referente al aprovechamiento hidroeléctrico de la cuenca del Plata, en el caso de la usina de Itaipú.

En tanto, el Brasil de la Nueva República, fiel a sus compromisos en el plano interno con la democracia y el cambio, entiende que el pacifismo de medios no es suficiente, pues en la última instancia la paz es una obra de la justicia que debe ser construída por la cooperación multilateral sustantiva y por el respeto al. Derecho 
Internacional. "Todos", como dice el artículo 28 de la Declaración Universal de los Derechos Humanos, "tienen derecho a un orden. social $e$ internacional en que los derechos y libertades establecidos en la presente declaración pueden ser plenamente realizados".

La plena realización de Ios derechos humanos en escala planetaria exige la reducción del hiato que hoy existe entre los países desarrollados y los subdesarrollados y la superación del absurdo contraste prevaleciente en el sistema internacional entre el exceso de poder, que creó condiciones estratégico-militares para una guerra de exterminio y el exceso de impotencia que, en el campo económico social, viene condenando a las grandes masas de la humanidad al hambre y a la miseria. Por esa razón la diplomacia brasileña, en la línea seguida por Itamaraty en el régimen militar, defiende las reivindicaciones de los países del Tercer Mundo en pro de un orden económico más justo y equitativo. Se entiende, en síntesis, que cabe al país desempeñar en conjunto con otros - con la legitimidad adicional derivada de su propuesta interna y con los recursos de poder de que dispone una potencia intermedia para catalizar iniciativas- un papel positivo en este amplio proceso de negociación que ahora está en curso. De ahí que conviene realizar algunos aspectos nuevos de la actuación del Brasil en el campo económico internacional.

El campo de las relaciones económicas dice respecto de la transferencia internacional de recursos, en la amplia aceptación de financiamientos, intereses, inversiones directas, tecnología y productos, ya sea por la acción transnacional de empresas ya sea por la acción interestatal.

Es. lo que se puede llamar el mundo del comercio. Éste, cuando se compara con el campo estratégico-militar, careció de importancia para el sistema internacional en la segunda postguerra, con la profundización de la "mundialización" de las economías nacionales. En este sentido, es interesante recordar que el Japón y Alemania Occidental, a través de la actuación en el mundo del comercio, lograron alcanzar pacíficamente un predominio que persiguieron en los años 30 por medios militares y cuyos resultados fueron catastróficos. Se explica así la importancia que adquirieron en el proceso internacional de transferencia de recursos, los NIc's asiáticos como Corea del Sur, Singapur y Taiwán.

En contraste con el campo estratégico militar, en el cual prevalece la bipolaridad EE.UU.-URSS, el campo económico se caracteriza por una multipolaridad en la cual los EE. UU. tienen una presencia preponderante. Ésta no es tan avasalladora como lo fue en los años 50 y 60, por la emergencia de nuevos centros como el Mercado Común Europeo o el Japón. Sin embargo, continúa siendo hegemónica en el plano financiero debido al papel del dólar en el mundo y es fun- 
damental en el plano económico, ya sea por la importancia del mercado norteamericano, ya sea por el impacto internacional de la reestructuración de la economía norteamericana que se viene configurando por la tecnologfa de punta, por los servicios y por la informática.

¿Cuáles son las posibilidades del Brasil de atender a sus necesidades internas y condicionamientos externos, actuando en el campo económico internacional? La respuesta a esta pregunta pasa por un análisis previo de lo que viene sucediendo en este campo y también de cuál ha sido el desempeño global de América Latina, donde Brasil se inserta, en este mundo del comercio.

Una de las características del mundo del comercio en los años 80 es la disminución de la importancia de los productos primarios. Eso ocurre en el campo de los alimentos, pues hoy, debido al éxito de la agricultura en el Mercado Común Europeo, en los EE. vU. y en muchos paises subdesarrollados, sólo la uRss es una gran importadora de alimentos. A eso cabe agregar las prácticas claramente proteccionistas adoptadas por los países desarrollados en la defensa de sus productos agrícolas. De ahí las consecuencias para Argentina y Uruguay, que se ven obligados a redefinir su papel clásico en la división internacional del trabajo, lo que es una de las razones para explicar la renovada importancia del comercio regional y de los dos recientes acuerdos entre Argentina, Uruguay y el Brasil. Esta disminución de importancia afecta igualmente a la economía cafetera, y en consecuencia al Brasil, Colombia y los paises de América Central, por fuerza de la disminución del consumo y de la "vis atractiva" del café. Lo mismo ocurre con el tabaco.

La disminución de la importancia de los productos primarios alcanza igualmente las materias primas, pues la innovación tecnológica está reduciendo su peso económico, ya sea en los procesos de manufactura -es el caso de la energía, inclusive el petróleo-, ya sea en la cantidad de materias empleadas, pues los productos son más leves y el plástico está sustituyendo a metales y fibras naturales. De eso también se derivan consecuencias para Venezuela y México en cuanto exportadores del petróleo, para Brasil en cuanto exportador de estaño y para Chile como exportador de cobre, para dar algunos ejemplos.

Otro punto importante es el hecho de que la competitividad del proceso industrial depende menos hoy del costo de la mano de obra, por fuerza de la automatización y de la informática, lo que torna menos competitiva a América Latina de lo que era antes en el mun. do del comercio.

La informática y la automatización también son responsables por una alteración de la industria manufacturera, pues permiten su división para efectos analíticos en dos tipos: la basada en materias 
primas que generan productos que aparecen en la balanza comercial y la basada en informaciones y conocimientos que no siempre surgen como productos y que frecuentemente aparecen como servicios. De ahí la razón por la cual, por insistencia de los EE. UU, que han predominado en este sector, el tema de los servicios ha sido insertado en la agenda del GATT. En sustancia, este fue el resultado de la reunión del GatT realizada en septiembre en Punta del Este. En esa reunión se logró una fórmula diplomática apropiada para salvaguardar las posiciones de países como el Brasil y la India que, como países subdesarrollados de mayor tamaño industrial y tecnológico, no querian abrir un proceso de negociación ni el estudio de los servicios sin una agenda preestablecida. Esta fórmula no elimina el hecho de que, con el apoyo del secretariado del GATI, se está iniciando el estudio y la discusión de servicios en el contexto de una nueva rueda de negociaciones comerciales multilaterales.

Es importante observar que la posición norteamericana en materia de servicios ha sido colocada básicamente como una cuestión de intereses especificos, cuantificables y negociables. En este sentido, la posición norteamericana comporta analogías con la postura del liberalismo económico que adopta en materia de Derecho del Mar, cuando en la primera presidencia de Reagan se rechaza el texto

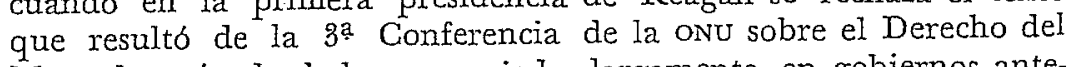
Mar, después de haber negociado largamente en gobiernos anteriores.

Para América Latina en general, la transformación de la industria manufacturera a través de la informática en términos de competitividad, choca con la falta de infraestructura de conocimientos y de educación y, para el Brasil en particular, añade el riesgo de obsolescencia de la estructura industrial de gran tamaño, fruto de las grandes inversiones de los años 70 . Es en este contexto que también debe ser entendida la política de reserva temporal de mercado en ciertos segmentos de la informática, que es uno de los conflictos delicados del país con los EE. UU. y con otras naciones desarrolladas. En efecto, esta política se inserta en una propuesta de política industrial que procura dar al país condiciones para una capacitación tecnológica que lo torne apto para introducirse en un mundo compatible con las nuevas realidades de este final del siglo $\mathrm{xx}$.

Finalmente cabe recalcar que, en los años 80 , la economía simbólica -o sea, los movimientos de capital, las tasas de cambio, los flujos de crédito- se vienen apartando cada vez más de la economía real de las transacciones y bienes de servicio. En este sentido, es suficiente recordar que el comercio mundial de bienes y servicios oscila entre us $\$ 2,5$ mil millones y us $\$ 3$ mil millones por año, números que no guardan ningún vínculo de proporcionalidad con los us\$ 75 mil millones que anualmente se mueven en el mercado fi- 
nanciero de los eurodólares. Estos números indican que los movimientos de capital -y no el comercio - se convirtieron en la fuerza que impulsa al comercio mundial.

Para el Brasil y para América Latina estas características generales infunden poco ánimo y se agravaron en los años 80 por fuerza del peso de los cargos de la deuda externa. En efecto, se alteró estructuralmente la situación de los años 80. Esta se caracteriza por el masivo ingreso de recursos en la región en la forma de financiamientos privados, que reciclaron los petrodólares. Estos recursos fueron, en el caso de Brasil, muy especificamente un factor de estimulo a las actividades económicas y una respuesta a la crisis de los precios del petróleo, transformándose además en algo aceptable financieramente para acreedores y deudores, en la medida en que las tasas internacionales de interés permanecieron en este período muy por debajo de las tasas de expansión de las exportaciones de los países receptores de estos recursos.

En Ios años 80 esta situación varió radicalmente con la inversión de la diferencia entre las tasas de crecimiento de las exportaciones de los países deudores y las tasas de interés internacionales. Éstas, como es sabido, subirán por fuerza del impacto de la desproporción entre las políticas monetaria y fiscal de los EE. uU. en todo el mundo. El ajuste de América Latina a esta nueva situación, señalada también por la descontaminación de las políticas macroeconómicas de los países desarrollados, convirtió a una región de economías subdesarrolladas - que necesitan ahorro externo para crecer- en exportadora líquida de capitales, compelida a generar enormes superávit comerciales para pagar los servicios de la deuda. Este esfuerzo de exportación provocado por la deuda en América Latina ha 1) causado serios perjuicios a su desarrollo; 2) agravado sus problemas sociales; 3) reducido sus exportaciones con consecuencias para el comercio internacional y, finalmente, 4) por los desequilibrios causados por la reducción de sus importaciones, ha estimulado las tendencias proteccionistas de los países desarrollados.

En este cuadro sombrío, a partir de 1984 y con nitidez en la Nueva República, el Brasil, por causa de su esfuerzo interno en sustituir importaciones de petróleo, y en el contexto de recuperación del comercio mundial y de la baja de las tasas de interés, obtuvo un excepcional desempeño económico. Como señaló el Presidente Sarney en su reciente artículo en Foreign Affairs, en estos dos años de su gestión el país creció, expandió sus reservas, produjo superávit comerciales anuales del orden de us $\$ 12$ mil millones, saldó los intereses de la deuda sin recibir dinero nuevo y sin un acuerdo con el Fondo Monetario Internacional, y pagó spreads altísimos, cuando se toma en cuenta que durante toda la crisis de endeudamiento de los años 80, ni bancos ni inversionistas perdieron dinero en el Brasil. 
El costo social y económico de este desempeño, único en América Latina, -en parte viabilizado por el hecho de que la relación de las importaciones con el PNB es de sólo un 6\% (3\% excluido el petróleo)- ha sido altísimo y amenaza la necesidad brasileña de enfrentar la desigualdad para poder consolidar la democracia. "La deuda se paga con miseria y la cuenta se paga con la democracia", afirmó el Presidente Sarney en su ya mencionado discurso de septiembre de 1985, en la apertura de los trabajos de la Asamblea General de Ia oNu. De hecho, no hay cómo encaminar adecuadamente el problema de la reducción de la desigualdad y el imperativo del crecimiento cuando se toma en cuenta que desde 1983 la economía brasileña produce más de lo que gasta en consumo y en inversión. Ella transfiere al exterior el equivalente al $5 \%$ del PIB para el pago de los intereses de la deuda y demás rendimientos de capital extranjero. En 1985, la transferencia de recursos al exterior alcanzó a US $\$ 11,4$ mil millones, o sea, siete veces lo que se gastó con el programa de prioridades sociales y una cuarta parte del ahorro interno bruto.

Con el objetivo de aclarar este dilema entre necesidades internas y exigencias externas, el Presidente Sarney, con ocasión de su visita a los EE. UU., en su discurso de septiembre de 1986 en la sesión conjunta del Congreso norteamericano, explicó que para crecer, Brasil necesita invertix e importar más, adquiriendo productos de sus socios comerciales y para invertir y exportar más, el Brasil precisa reducir su saldo comercial con el exterior. Si el país reduce su saldo comercial, disminuirá su capacidad de transferir recursos para el pago de la deuda, lo que sólo podría hacer si pudiera pagar menos, por algún tiempo, para importar más. De ahí la conclusión: "Solamente así podemos a egurar de inmediato el ritmo de crecimiento ansiado y, a mediano y largo plazos, la reintegración del país en la economía internacional, sin crisis, choques ni sobresaltos, y cumplir con el ineludible compromiso que tenemos con nuestro pueblo".

En sintesis, la posición brasileña reitera que no es posible tratar de finanzas y comercio como si fuesen compartimentos estancos en el proceso de transferencia internacional de recursos. En este sentido, la acción independiente del GATT y del FMr como instancias ordenadoras de la economía mundial de mercado está perdiendo -frente a las nuevas realidades ya reseñadas en forma sucinta- la capacidad de regular el contexto dentro del cual operan los protagonistas de la transferencia internacional de recursos. De ahí el empeño de la Nueva República de mantener y aumentar sus márgenes de autonomía, sin someterse al monitoreo del FMr.

La postura actual brasileña en lo referente al FMr, que contrasta con la del régimen militar, no significa un rechazo del principio democrático de la transparencia de conducta, indispensable en cual- 
quier proceso de cooperación efectiva internacional. Brasil, conforme a lo ya señalado, está aceptando rendir cuentas a la comunidad internacional en una materia tan delicada como la de los derechos humanos, que se relaciona con la cualidad del ejercicio de poder. Significa esto que en la visión brasileña, las condicionalidades del FMI en el momento actual, se traduce en una "receta" que no cons" tituye un patrón de conducta celosa y responsable. E-ta receta, basada esencialmente en la reducción del consumo interno y de las exportaciones, impondría al país una "obligación de comportamiento" que no sólo disminuirá los riesgos que acarrea la deuda al sistema financiero internacional, sino que también podrá llevar a un fracaso interno del poder, o sea, al derroche de recursos materiales y sociales en la consecución de acciones y programas que sobrevalorizan el repertorio de recuerdos y prescripciones pasadas, subestimando nuevos datos $y$ nuevas informaciones.

En este nuevo esfuerzo diplomático, que señala un importante cambio de actitud, el Brasil va tratando de persuadir y presionar a sus interlocutores estatales y transnacionales - para poder negociar mejor su inserción en el campo económico- de que la posición del país tiene un alcance más amplio. Éste se refiere al hecho de que un nuevo aspecto de la crisis del sistema internacional es la conversión de pafses subdesarrollados en exportadores líquidos de capital. Esta crisis, señalada por un quiebre entre poder y orden -este último entendido como un patrón previsible de conducta-, significa la ausencia de reglas razonables para la acción en el campo económico que estén a disposición de los gobernantes. Eso representa una águdización del problema de la gobernabilidad del sistema internacional y por tanto, una amenaza tangible para el precario orden mundial.

Evidentemente, en esta perspectiva más amplia, la pregunta se plantea en el sentido de saber si el mundo del comercio frente a esta crisis se traducirá en una lucha de todoi por todos, que hará más pacffica a la humanidad al volverse las naciones útiles unas a otras o, al contrario, representará una lucha de todos contra todos, destructiva del orden mundial, que podrá verse amenazada por la sublevación de los particularismos.

En efecto, la estabilidad del orden mundial, tanto en el campo estratégico militar como en el económico, presupone una aceptación del cuadro de funcionamiento del sistema internacional.

Esta aceptación no impide el conflicto, pero limita su alcance, pues la acomodación de los conflictos a través de la diplomacia sólo es posible cuando el orden vigente es percibido como mínimamente razonable. De hecho, la diplomacia al transitar por la persuasión, presume un cuadro común de referencias en cuanto a lo que es aceptable, ya sea en términos de valores e intereses comunes, ya seà 
en términos de una interpretación compartida sobre relaciones de poder.

En este sentido, vale la pena ponderar que ocurrirán redistribuciones de poder en el sistema internacional. Esas redistribuciones disminuirán la capacidad de las grandes potencias de administrar por sí solas el orden mundial, ya sea porque existen problemas de enfoque universal, como la ecología, el tráfico de drogas y el terrorismo, ya sea porque el campo económico efectivamente se internacionalizó. Esa es una situación nueva que caracteriza el sistema internacional a partir de la década del 60 y explica no sólo el espacio abierto al tema Norte-Sur, sino las dificultades de estructurar la vida internacional en torno a las relaciones Este-Oeste. Por eso, en última instancia, la posición brasileña consigna la siguiente pregunta: ¿es posible un orden estable si los grandes paíes deudores, en particular los de América Latina, están insatisfechos?

No es fácil responder a esa pregunta, pues ella requiere la serenidad de muchos protagonistas - estatales y transnacionales- para reflexionar sobre la complejidad de la crisis, cuya sustancia es de difícil comprensión. Ella ayuda, sin embargo, a explicar la conducta brasileña y lo que ella contiene de nuevo, por causa de los cambios internos y de su impacto en el campo de valores. Esto sucede no sólo en el campo económico general, sino también en el contexto regional latinoamericano, que ahora examinaré, como último tópico de este artículo.

El contexto diplomático del Brasil es el de América Latina, una región que combina geografía e historja y tiene una agenda común de temas y problemas derivados de formas compartidas de inserción en el sistema internacional. Se trata de una región que, en su interacción, está buscando, sobre todo a partir de los años 50 , un repertorio común de intereses convergentes, intentando superar sus dificultades de cooperación, que se der:van tanto de los desajustes de los ciclos económicos y políticos como de las diferencias de escala que separan a los países de la región. Ese esfuerzo de cooperación proviene de la percepción de una interdependencia recíproca, pues lo que acontece en un país afecta e influencia a los demás, ya en el campo de los valores -es el caso del proceso de democratización- ya en el campo estratégico-militar- son los problemas territoriales o el terrorismo -además en el campo económico- es el caso de la deuda o de la reducción del comercio intralatinoamericano, por causa de la crisis de recesión de los años 80 .

En síntesis, se trata de un contexto diplomático privilegiado por sus integrantes, pues los países latinoamericanos se perciben como aliados, mercados y modelos relevantes unos para los otros, sin los cuales difícilmente sobrevivirían como unidades autónomas en el sistema internacional. 
En el momento actual, los items prioritarios de la región son los problemas de la democratización y de la causa, que se insertan, a su vez, en los cambios ocurridos en el mundo del comercio que bicieron que la región, entre 1950 y 1985 , perdiese posición en el campo económico. En 1950, Argentina, Brasil, Chile, Colombia, Ecuador, México, Perú, Uruguay y Venezuela tesían una renta per cápita más alta que Corea del Sur y Taiwán; Venezuela, Uruguay y Argentina estaban al frente de Austria y de Italia; la mayoría de los países latinoamericanos sobrepasaban a Grecia, Portugal y Turquía. Hasta 1960, muchos países latinoamericanos estaban al frente del Japón o se igualaban con él.

En 1985, la renta media de Ios países latinoamericanos a que nos hemos referido fue un tercio menos que la del Japón y de los países europeos medios, la mitad de Ia de los países de la Europa Mediterránea y por debajo de la de las naciones recientemente industrializadas de Asia y de Turquía.

Eso explica la acción conjunta, sea en la modalidad de una definición común -ejemplificada en el Consenso de Cartagena para el tratamiento de los problemas de orden general de la deuda internacional de los países latinoamericanos-, sea en la modalidad de nuevos mecanismos de cooperación regional con vistas a la creación de un espacio económico ampliado, a través de un mercado común. $\mathrm{El}$ aspecto más interesante y nuevo de este esfuerzo de cooperación son los acuerdos recientes entre Argentina y el Brasil, a los cuales se asoció Uruguay, que pretenden eliminar barreras adueneras, promover el intercambio de bienes y servicios y estimular proyectos industriales comunes.

Estos acuerdos son vistos en su conjunto como una respuesta apropiada a la necesidad interna común que proviene del desafío del crecimiento, de la viabilidad democrática y de la pérdida de posición relativa en el mundo en el campo económico. Estos acuerdos forman un núcleo estructural para un nuevo espacio preferencial regional, al que con el correr del tiempo podrían asociarse otros países latinoamericanos, con el objetivo de conferir a América Latina no su perfil -que ella ya lo tenía- sino el rostro de su individualidad en el mundo, por medio de un papel activo en la redefinición del orden mundial, con especial atención al campo de los valores de inspiración democrática; en el campo estratégico, a los consejos de paz y en el campo económico, a un orden más justo, más equitativo y más eficiente. 